\title{
Frank Uekötter, Deutschland in Grün. Eine zwiespältige Erfolgsgeschichte
}

\section{Céline-Agathe Caro}

\section{OpenEdition}

\section{Journals}

Édition électronique

URL : http://journals.openedition.org/ifha/8560

DOI : $10.4000 /$ ifha. 8560

ISSN : 2198-8943

\section{Éditeur}

IFRA - Institut franco-allemand (sciences historiques et sociales)

\section{Référence électronique}

Céline-Agathe Caro, « Frank Uekötter, Deutschland in Grün. Eine zwiespältige Erfolgsgeschichte », Revue de l'IFHA [En ligne], Date de recension, mis en ligne le 01 février 2017, consulté le 24 septembre 2020 URL : http://journals.openedition.org/ifha/8560 ; DOI : https://doi.org/10.4000/ifha.8560

Ce document a été généré automatiquement le 24 septembre 2020

(CIFHA 


\title{
Frank Uekötter, Deutschland in Grün. Eine zwiespältige Erfolgsgeschichte
}

\author{
Céline-Agathe Caro
}

\section{RÉFÉRENCE}

Frank Uekötter, Deutschland in Grün. Eine zwiespältige Erfolgsgeschichte, Göttingen: V\&R Academics, 2015, 294 p., $30 €$ 
Ce livre de Frank Uekötter est la traduction allemande, revue et complétée, d'un ouvrage publié par l'auteur en anglais en 2014 sous le titre The Greenest Nation? A New History of German Environmentalism (MIT Press) - cet ouvrage reprenant lui-même le premier chapitre de l'une de ses publications précédentes: Am Ende der Gewissheiten. Die ökologische Frage im 21. Jahrhundert (Campus Verlag, 2011).

La particularité de ce troisième opus, dont on pourrait traduire le titre par «L'Allemagne en vert. Un succès à nuancer", est qu'il ne s'attache pas à présenter l'histoire des mouvements écologistes allemands, comme c'est souvent le cas des analyses consacrées à l'écologie en Allemagne. Le sujet de l'auteur n'est pas «l'Allemagne verte»:

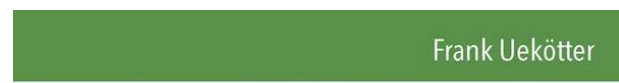

\section{Deutschland in Grün}

Eine zwiespältige Erfolgsgeschichte

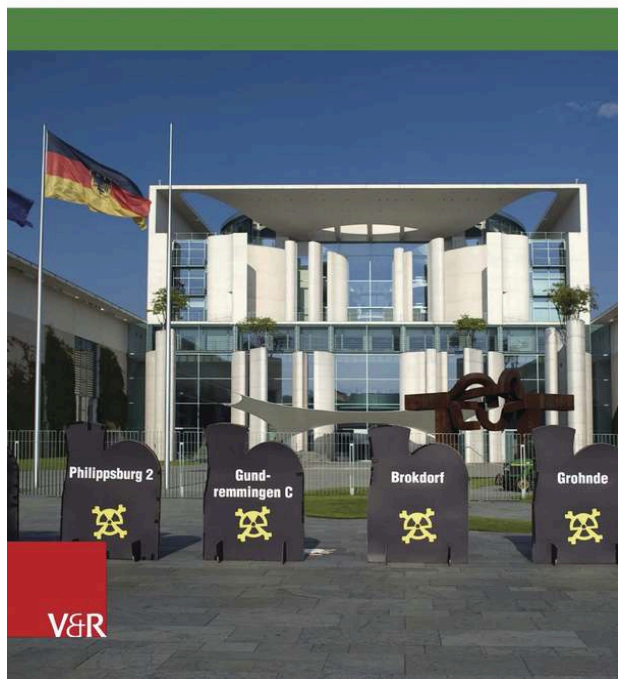
ce livre ne retrace pas l'histoire des différentes associations de protection de la nature et de l'environnement qui ont vu le jour outre-Rhin à partir de la fin du XIX siècle. Il n'évoque qu'en passant les initiatives de citoyens et les listes vertes qui sont entrées dans la sphère politique en RFA à partir des années 1970 et qui ont donné naissance, en janvier 1980, au parti écologiste Die Grünen. F. Uekötter s'intéresse ici à " l'Allemagne en vert ", c'est-à-dire à la façon dont le pays dans son ensemble s'est transformé au fil des décennies dans son interaction avec les questions environnementales et les réponses qui, à chaque époque, ont été apportées aux défis les plus pressants.

L'ouvrage retrace ainsi l'histoire de la protection de l'environnement en Allemagne depuis l'Empire allemand (1871-1918) jusqu'à la coalition rouge-verte, au pouvoir de 1998 à 2005, qui a vu le parti écologiste participer à deux gouvernements fédéraux. Douze chapitres d'une vingtaine de pages chacun présentent de façon chronologique les étapes les plus importantes de la mise en place de législations environnementales. L'auteur passe rapidement sur la fin du $\mathrm{XIX}^{\mathrm{e}}$ et la première moitié du $\mathrm{XX}^{\mathrm{e}}$ siècle, avec un chapitre sur l'Empire et un sur « les années de crise ", englobant à la fois la Première Guerre mondiale, l'entre-deux-guerres et la Seconde Guerre mondiale, abordant le rapport complexe du régime national-socialiste à la nature. Il consacre ensuite un chapitre aux années 1950-1960 portées par le miracle économique, un chapitre aux années 1970, celles de profonds bouleversements de société et de violentes manifestations contre la construction de centrales nucléaires, et un chapitre aux années 1980 qui marquent l'envol de l'écologie sur la scène politique nationale. Un chapitre d'une quinzaine de pages est aussi consacré à la politique environnementale de la RDA, et en particulier aux problèmes structurels qui ont limité son développement. Pour finir, un dernier chapitre chronologique survole vingt-cinq ans de questions écologiques en Allemagne depuis 1990. 
Cet ouvrage se concentre donc sur la mise en place de politiques vertes outre-Rhin depuis les années 1960 jusqu'au début des années 1990. Il ne constitue pas un ouvrage de droit qui étudierait les lois et leur mise en application. Pour chaque époque, l'approche méthodologique de F. Uekötter s'appuie sur le concept des champs d'action développé par Pierre Bourdieu. Il en décompte trois pour son sujet: l'influence des acteurs étatiques, au niveau national ou communal, l'influence de la société civile et le champ de la sphère de vie ("Lebenswelt»), à savoir l'évolution des mentalités et des modes de vie. L'auteur s'attache à démontrer comment ces trois champs d'action interagissent entre eux et comment ils ont contribué, ensemble, à faire de l'Allemagne l'un des pays les plus soucieux, à l'échelle internationale, de la protection de la nature et de l'environnement.

Deux chapitres sont également consacrés à l'internationalisation des débats environnementaux dès la fin des années 1940, notamment autour de grands défis internationaux - comme les répercussions pour la nature et la santé publique des essais nucléaires - ou d'ouvrages scientifiques qui ont marqué leur époque, à l'instar du bestseller de Rachel Carson sur le produit chimique DDT, Le Printemps silencieux, sorti en 1962. Ces deux chapitres (l'un pour les années 1945-1973, l'autre pour la période 1987-1992) visent à inscrire les discussions allemandes dans un contexte scientifique, politique et économique au-delà des frontières nationales et à mettre en valeur les influences réciproques. Ils se terminent avec le "Sommet de la Terre" de Rio de Janeiro (Brésil) organisé en 1992 qui a entériné l'arrivée de l'écologie sur la scène politique mondiale et qui a lancé une politique institutionnelle de développement durable au niveau national, européen et mondial. Le sous-titre de l'ouvrage (traduit ici librement par "Un succès à nuancer») nous indique dès le début la tonalité de la conclusion : si l'écologie a pu s'imposer en Allemagne et sur la scène internationale au niveau politique, les résultats globaux - en particulier en matière de changement climatique et de protection de la biodiversité - sont encore loin d'être satisfaisants.

Cet ouvrage relativement court et bien documenté constitue un bon survol des principales étapes qui jalonnent l'histoire environnementale de l'Allemagne. Les comparaisons internationales qui accompagnent l'analyse permettent de mieux cerner ce qui fait la particularité de ce pays en matière d'écologie et de développement durable. Le lecteur restera peut-être sur sa faim face à certaines analyses trop rapides, comme celle des répercussions de Mai 68 sur le mouvement écologiste ou celle de la politique environnementale de l'Allemagne depuis 2005. Mais l'ouvrage de F. Uekötter présente la grande qualité de donner envie d'en savoir plus sur ce phénomène allemand - qui étonne encore tellement à l'étranger.

\section{INDEX}

Index chronologique : Époque contemporaine

Thèmes : Histoire des idées 


\section{AUTEURS}

CÉLINE-AGATHE CARO

Senior Policy Analyst à la Fondation Konrad Adenauer à Washington 